\title{
"A Study of Mentzer Index as Screening Tool for Diagnosis of Beta Thalassemia Trait in Microcytic Hypochromic Anemia"
}

\author{
Dr. Dhiral Bhupatbhai Kavad ${ }^{1 *}$, Dr. Chandrika G. Algotar ${ }^{2}$, Dr. Neelam K. Mori ${ }^{3}$, Dr. Siddhartha D. Ghelani ${ }^{4}$
}

${ }^{1} 2^{\text {nd }}$ year Resident Doctor, ${ }^{2}$ Associate Professor, ${ }^{3}$ Assistant Professor, ${ }^{4}$ Assiatant Professor, Department of Pathology, C. U. Shah Medical College Dudhrej Road, Surendranagar, India

DOI: $10.36347 /$ sjams.2020.v08i12.026

| Received: 19.10 .2020 | Accepted: 30.10 .2020 | Published: 24.12.2020

*Corresponding author: Dr. Dhiral Bhupatbhai Kavad

Abstract

Original Research Article

Context: Beta thalassemia trait (beta-TT) is common among Indian population especially among communities like Sindhis, Bengalis and Gujaratis (Lohanas). Individuals having beta-TT have mild Microcytic Hypochromic Anemia (MCHCA) and asymptomatic course same as that of Iron Deficiency Anemia (IDA). The aim of our study is to evaluate the reliability of Mentzer index as a screening tool in diagnosis of beta-TT and differentiate between other causes of MCHCA. Aim: To study the reliability of Mentzer index as a screening tool for diagnosis of beta thalassemia trait. Methods and Material: The data were taken from 100 patients of Microcytic Hypochromic Anemia at Green Cross laboratory, C. U. Shah Medical College and Hospital, who underwent CBC (Complete Blood Count) and $\mathrm{Hb}$ electrophoresis. Statistical analysis used: Sensitivity, Specificity, Positive predictive value (PPV), Negative predictive value (NPV). Results: The blood samples of 100 patients (Age: 0-26 years), who are included in the study, were run through a 5-part cell counter which revealed Hb, PCV, MCV and RDW of each sample. The peripheral smear examination of the samples revealed the finding of Microcytic Hypochromic Anemia. All 100 blood samples then studied for $\mathrm{Hb}$ electrophoresis. Out of 100 patients 58 patients had Mentzer index <13, out of which 43 patients were diagnosed with beta thalassemia trait by $\mathrm{Hb}$ electrophoresi ( $\mathrm{Hb} \mathrm{A} 2>3.5 \%$ ). Conclusions: Mentzer index is a reliable screening tool for diagnosis of beta-TT and it can be used as a screening tool at small setups and at peripheral areas where $\mathrm{Hb}$ electrophoresis is not readily available.

Keywords: Beta Thalassemia Trait (beta-TT), Mentzer Index, Screening Tool.

Copyright $(\mathcal{C} 2020$ The Author(s): This is an open-access article distributed under the terms of the Creative Commons Attribution 4.0 International License (CC BY-NC 4.0) which permits unrestricted use, distribution, and reproduction in any medium for non-commercial use provided the original author and source are credited.

\section{INTRODUCTION}

Thalassemia is th most common genetic disorder worldwide. WHO reported that $5 \%$ of the world's population i thalassemia carriers [1]. Beta thalassemia trait (beta-TT) is common among Indian population especially among communities like Sindhis, Bengalis and Gujaratis (Lohanas, Kachchhis). Thalassemia results from impaired globin chain synthesis and decreased hemoglobin ( $\mathrm{Hb}$ ) synthesis, resulting in microcytosis and hypochromia. $1.5 \%$ of the world's population carries genes for $\beta$-thalassemia [2]. While the diagnosis of beta thalassemia major usually becomes obvious within initial years of life because of progressive anemia, it is children with beta thalassemia trait who pose a diagnostic dilemma [3, 4].

Iron deficiency anemia (IDA) is also a very common in Indian population. So, it is of utmost importance to differentiate children having microcytic hypochromic anemia due to thalassemia trait from those due to iron deficiency anemia because of obvious implications beta-TT will have on management of these children [5].

A definitive diagnosis of beta-TT based on the result of $\mathrm{HbA} 2$ electrophoresis. Primary screening tests to evaluate thalassemia are Complete Blood Count (CBC) and other blood indices. One of the examination parameters that can be used for thalassemia carrier screening test is Mentzer index. Mentzer index is calculated using the following formula.

\section{Mentzer index $=$ MCV (fL) $x 100 /$ RBCCount (millions per microlitre) \\ Mentzer index is an $\mathrm{MCV} / \mathrm{RBC}$ ratio calculation in which patient with a value of $<13$ is diagnosed as thalassemia carriers while a value of $>13$ is found in patients with iron deficiency $[6,7]$.}

\section{SubJECTS ANd Methods}

In this study, the data were taken from 100 patients of Microcytic Hypochromic Anemia at Green 
Cross laboratory, C. U. Shah Medical College and Hospital, who underwent CBC (Complete Blood Count) and $\mathrm{Hb}$ electrophoresis examination between august 2019 and october 2020. The blood samples of 100 patients (Age group 0-26 years) who are included in the study were taken in EDTA vaccuate, run through a 5 part cell counter which revealed $\mathrm{Hb}, \mathrm{PCV}, \mathrm{MCV}, \mathrm{MCH}$ and RDW of each sample.

Mentzer index (MCV/RBC) calculation was done of all the samples. The peripheral smears of all the samples were examined under microscope which revealed the finding of Microcytic Hypochromic Anemia.

All 100 blood samples then studied for $\mathrm{Hb}$ electrophoresis and results of it were compared to the results of Mentzer index.

\section{Inclusion criteria}

a) Age group 0 to 26 years

b) Patients diagnosed with microcytic hypochromic anemia.

\section{Exclusion criteria}

a) Coexistence of other hematological condition like autoimmune hemolytic anemia, aplastic anemia, sickle cell disease or lead intoxication.

b) History of blood transfusion in near past

\section{RESULTS AND DISCUSSION}

The blood samples of 100 patients who were included in the study were run through a 5 part cell counter which revealed decreased $\mathrm{Hb}$, PCV, MCV, $\mathrm{MCH}$ and MCHC. The complete blood count indices and peripheral smear examination of these 100 patients revealed microcytic hypochromic anemia.

Out of 100 patients with microcytic hypochromic anemia, 58 patients had Mentzer index less than 13. All these blood samples then tested for $\mathrm{Hb}$ electrophoresis. Out of 58 patients with Mentzer index less than 13, 43 patients were diagnosed with beta-TT by $\mathrm{Hb}$ electrophoresis ( $\mathrm{Hb} \mathrm{A} 2$ more than $3.5 \%$ ). Out of 42 patients with Mentzer index more than 13, 2 patients were diagnosed with beta-TT by $\mathrm{Hb}$ electrophoresis.

Sensitivity is the measure of probability that a test will indicate 'disease' among those who are having the disease while specificity is the fraction of those patients without disease who will have a negative test result with gold standard test. Positive predictive value indicates proportion of true positive cases which gives positive results on both screening test and gold standard test while negative predictive value indicates proportion of true negative cases which gives negative results on both screening test and gold standard test. Accuracy indicates the ability of a test to identify true positive and true negative results.

\begin{tabular}{|c|c|c|c|}
\hline \multirow{2}{*}{ Mentzer index of patients with MCHCA } & \multicolumn{2}{|c|}{ Beta-TT in Hb electrophoresis } & \multirow{2}{*}{ Total } \\
\cline { 2 - 3 } & Yes & No & \\
\hline$<13$ & 43 & 15 & 58 \\
\hline$>13$ & 02 & 40 & 42 \\
\hline Total & 45 & 55 & 100 \\
\hline
\end{tabular}

In our study, Mentzer index was found to be reliable to diagnose beta-TT with sensitivity of $95.5 \%$, specificity of $72.7 \%$, positive predictive value of $74.13 \%$, and negative predictive value of $95.23 \%$ and accuracy of $83 \%$. This indicates the reliability of Mentzer index in diagnosis of beta-TT as it rarely misdiagnoses those who are not having beta-TT.

Beta-TT and IDA are among the most common causes of microcytic hypochromic anemia encountered in India. Distinguishing beta-TT from IDA has important clinical implications because each disease has an entirely different cause, prognosis, and treatment. Patients of beta-TT are usually asymptomatic or they present with similar clinical picture as that of IDA. Misdiagnosis of beta-TT has consequences for offspring leading to beta thalassemia disease.

In iron deficiency anemia reduced PCV, MCV, $\mathrm{MCH}$, and $\mathrm{MCHC}$ are seen but the diagnosis is confirmed by carrying out iron studies. The classical findings seen in iron deficiency anemia are reduced serum ferritin and serum iron and increased total iron binding capacity. Confirm diagnosis of beta-TT can be done by measuring the $\mathrm{HbA} 2$ concentration of lysed RBCs via Hb electrophoresis. Therefore, it is necessary to select appropriate individual for a detailed examination on basis of CBC \& Mentzer index. The diagnosis of thalassemia is dependent upon demonstration of increased $\mathrm{HbA} 2$ levels in blood (> $3.5 \%$ ) on $\mathrm{Hb}$ electrophoresis and mutation analysis [8].

Though the definitive test for thalassemia is $\mathrm{Hb}$ electrophoresis, it is difficult to perform this test in all patients as they are costly. Also $\mathrm{Hb}$ electrophoresis is not readily available at smaller setups in peripheral areas. For this reason Mentzer index is used as a diagnostic screening tool to differentiate between iron deficiency anemia and thalassemia trait [9].

In 2009, Ehsani et al. showed that the best discrimination index according to Youden's criteria was the Mentzer index $(90.1 \%)$, followed by the Ehsani et al. index $(85.5 \%)$. In their study, the Mentzer and Ehsani et al. wer able to correctly diagnose $94.7 \%$ and $92.9 \%$ of cases, respectively [10]. 


\section{REFERENCES}

1. Shivashankara AR, Jailkhani R, Kini A. Hemoglobinopathies in Dharwad, North Karnataka: a hospital-based study. Journal of Clinical and Diagnostic Research. 2008, 2: 593-599.

2. Rathod DA, Kaur A, Patel V, Patel K, Kabrawala R, Patel V, Patel M, Shah P. Usefulness of cell counter-based parameters and formulas in detection of $\beta$-thalassemia trait in areas of high prevalence. American journal of clinical pathology. 2007 Oct 1;128(4):585-9.

3. Yates AM, Mortier NA, Hyde KS, Hankins JS, Ware RE. The diagnostic dilemma of congenital unstable hemoglobinopathies. Pediatric blood \& cancer. 2010 Dec 15;55(7):1393-5.

4. Bose S, Maimoon S. Is Mentzer index a reliable diagnostic screening tool for beta thalassemia trait. IOS-JDMS. 2018;17(7):711.

5. Karimi M, Cohan N, De Sanctis V, Mallat NS, Taher A. Guidelines for diagnosis and management of Beta-thalassemia intermedia. PediatrHematolOncol. 2014Oct; 31(7):583-96

6. Mousa AO. Types of Anemias with Low MCV Using Mentzer Index and RBC Count among
Patients Seen in Basrah Al-Sadir Teaching Hospital. Medical Journal of Babylon. 2014, 11(2): $292-296$.

7. Sharma AK, Mehta S, Sharma S. Utility of Erythrocyte Indices For Screening of $\beta$ Thalassemia Trait In Pregnant Women Attending Antenatal Clinic. International Journal of Medical Science and Education. 2016, 3(4): 331 - 337.

8. Brancaleoni V, Di Pierro E, Motta I, Cappellini MD. Laboratory diagnosis of thalassemia.Int J Lab Hematol. 2016 May;38Suppl 1:32-40

9. Zaghloul A, Al-Bukhari TA, Bajuaifer N, Shalaby M, Al-Pakistani HA, Halawani SH, Teama SH, Wassif GA. Introduction of new formulas and evaluation of theprevious red blood cell indices and formulas in the differentiation between beta thalassemia trait and iron deficiency anemia in the Makkah region. Hematology. 2016 Jul;21(6):351-8.

10. Ehsani MA, Shahgholi E, Rahiminejad MS, Seighali F, Rashidi A. A new index for discrimination between iron deficiency anemia and beta-thalassemia minor: results in 284 patients. Pakistan Journal of Biological Sciences. 2009;12(5):473-5. 